\title{
Sigmoid Volvulus in Pregnancy
}

\author{
Major J C Allen \\ FRCS (Glas) \\ Registrar in General Surgery \\ Department of Surgery, Cambridge Military Hospital, Aldershot, Hampshire
}

SUMMARY: Sigmoid volvulus is uncommon in the U.K. and more so in pregnancy. A case of sigmoid volvulus in $\frac{\overline{\bar{O}}}{\mathrm{~s}}$
pregnancy with a rare successful conclusion by conservative management is described and discussed, with a review of the
literature.

Sigmoid volvulus in the U.K. accounts for only $0.9 \%$ of all cases of intestinal obstruction, with most cases occurring ing the elderly ${ }^{1}$. Intestinal obstruction in pregnancy is also uncommon, with a reported incidence varying between 1 in 3,600 maternities to 1 in 66,431 maternities ${ }^{2}$. A case is reported which was successfully treated conservatively.

\section{Case Report}

A 34 year old Caucasian was admitted as an emergency at the 30th week of her third pregnancy with severe lower abdominal pain. She gave a two day history of colicky lower abdominal pain, constipation (initially relative and then becoming absolute) vomiting and abdominal distention. There was no history of previous abdominal surgery and her two previous pregnancies had been uncomplicated, ending in normal full-term deliveries.

Examination showed her to be in severe pain with a distended, tympanitic abdomen and bowel sounds suggestive of intestinal obstruction.

The uterus was enlarged and compatible with a 30 week pregnancy. Rectal examination revealed an empty rectum and there were no external herniae. Plain abdominal X-ray confirmed the diagnosis of large bowel obstruction with a singleton pregnancy (Fig 1). An intravenous infusion was started and a nasogastric tube passed. Later that day screening with barium showed the 'beak' of a sigmoid volvulus (Fig 2).

The volvulus was then successfully deflated by passing a soft rubber flatus tube via the sigmoidoscope. The tube was taped in place, and kept clear by regular saline washouts. It was removed after 48 hours when her bowel sounds and abdominal X-ray had returned to normal. She remained in hospital for a further week without incident and was then allowed home on regular bulk laxatives. The pregnancy proceeded uneventfully and she subsequently had a normal delivery of healthy $3.75 \mathrm{~kg}$ male infant.

Four months post-partum an elective sigmoid colectomy was successfully performed. At operation the sigmoid colon was found to be held partially rotated by adhesions and $40 \mathrm{cms}$ of redundant colon was excised. She made a straightforward post-operative recovery and was fit and well on review two months later.

\section{Discussion}

Sigmoid volvulus as a cause of intestinal obstruction in pregnancy is rare, with only 70 cases reported worldwide ${ }^{2-10}$. There have been 15 cases of volvulus in

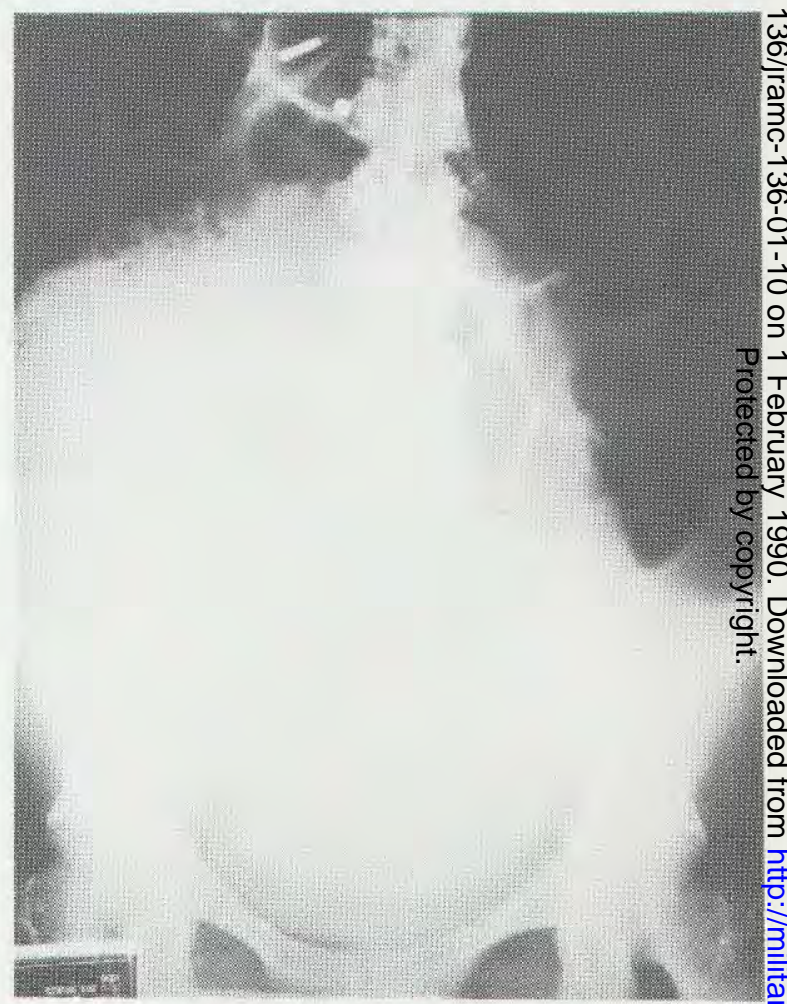

Fig 1. Abdominal film showing distended large bowel with gravid uterus.

pregnancy reported from the UK, of which only involved the sigmoid colon ${ }^{6,10-13}$. However, volvulus is a을 common cause of intestinal obstruction in pregnancy accounting in one review for nearly $25 \%$ of $\operatorname{cases}^{14}, \frac{2}{\supset}$ although this proportion may be declining ${ }^{2}$. Sigmoid volvulus is very rare in the non-gravid female of childbearing age, and in the pregnant woman occurs most $\widetilde{\sigma}$ often in the third trimester. Harer and Harer $^{14}$ surmised $_{N}$ that this may be due to the increasing size of the uterus elevating a mobile sigmoid colon from the pelvis and 


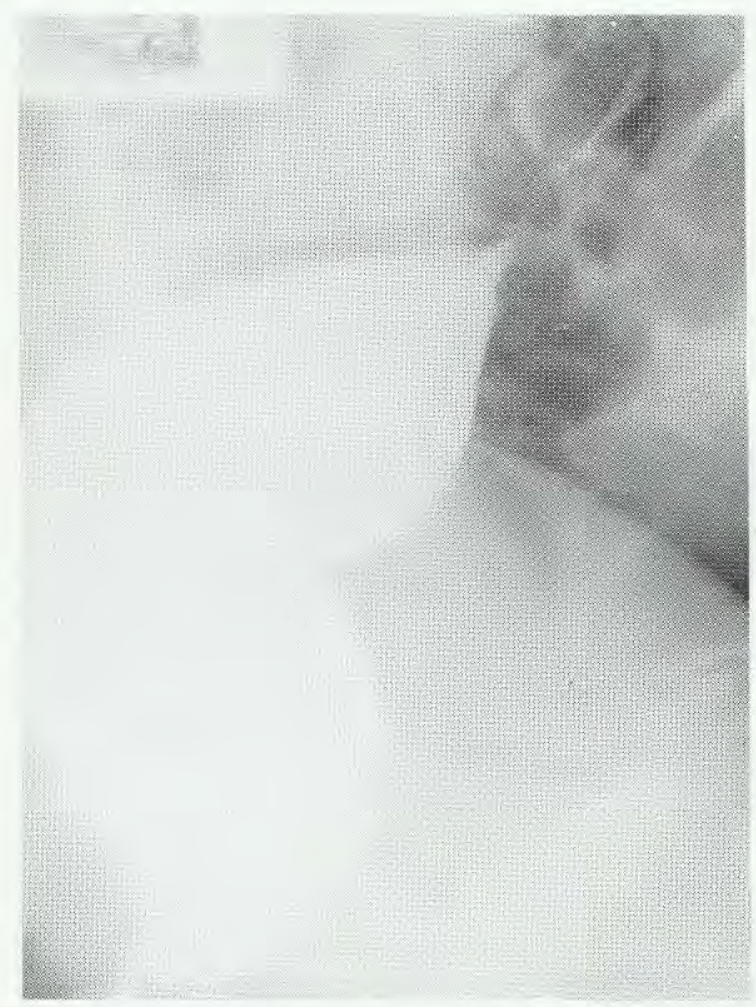

Fig 2. Barium screening demonstrating the 'beak' of a sigmoid volvulus.

producing a partial obstruction either due to pressure or kinking of the bowel. Proximal distension then causes the bowel to volve.

The first report appears to have been a postmortem, one by Braun in $1885^{5}$. In the majority of reported cases the diagnosis has been made at laparotomy and the procedure has ranged from simple detorsion and insertion of a rectal tube to resection with colostomy, with or without an initial Caesarian section.

Several authors urge laparotomy as the treatment of choice $^{12,14,16}$. However, in the last review of the condition the foetal loss associated with such a procedure was considered to be about $30 \%^{2}$. In the nonpregnant patient conservative management by decompression via a tube inserted through a sigmoidoscope is successful in between 50 and $88 \%$ of cases $^{17,18}$. This manoeuvre has been attempted on pregnant patients before ${ }^{6}$, but has apparently been successful on only one previous occasion ${ }^{19}$.

It is suggested that conservative management probably presents little danger to the pregnancy and is worth attempting before surgical intervention, provided the diagnosis can be made pre-operatively.

\section{REFERENCES}

1. BaLlantYNe G H. Review of Sigmoid Volvulus; Clinical Patterns and Pathogenesis. Dis Colon Rectum 1982; 25: 2 823-830.

2. LAZAROE J, DAS P B and ABraham P V. Volvulus of the sigmoid colon complicating pregnancy. Obstet Gynecoles 1969; 33: 553-557.

3. WAPNiCK S, MUfUNdi F and MUSENGESI L. Aetiological factors related to Intestinal Volvulus. Cent A fr J Med 1975; 21: $53-57$.

4. Hol.t.AND G A. Unusual case of intestinal obstruction in $\overline{\bar{c}}$ late pregnancy. Can Med Assoc J 1978; 118: 1488-1493.

5. ROLES N C. Volvulus of the intestine during pregnancy. East Afr Med J 1965; 42: 340-343.

6. KEATING I P and JACKSOY D S. Sigmoid volvulus in pregnancy. J R Army Med Corps 1985: 131: 72-74.

7. HofMeyr G J and SONNENDECKer E W W. Sigmoid volvulus in advanced pregnancy. $S$ Afr Med J 1985; 67: 63-64.

8. Agrawal R L and MisRa M K. Volvulus of the Sigmoid Colon. Int Surg 1971; 55 4: 49-56.

9. FRASER J L and ECKERT L A. Volvulus complicating pregnancy. Can Med Assoc I 1983: 128: 1045-1048.

10. Morris E D. Intestinal Obstruction and pregnancy. Obstet Gynaecol Br Comm 1965; 72: 36-44.

11. DONALD C. Volvulus of small gut, caccum and ascendin colon associated with congenital reversed rotation and with pregancy. Br J Surg 1927; 15: 269-272.

12. GoODAiL A L and Weir A W G. Volvulus complicatof? pregnancy and the puerperium. I Obstet Gynaecol Br Eब 1958: 65: 778-781.

13. Donaldson M. Pregnancy complicated by volvulus of sigmoid flexure causing intestinal obstruction. $\mathrm{Br}$ met 1919; 2: 774

14. HaRer W B and Harer W B. Volvulus complica pregnancy and the puerperium. Obstet Gynecol 1958; 399-406.

15. BRAUN G. Die Enterostenosen in Threr Beziehung zur Graviditaet und Geburt. Wien Med Wochenschr 1885; 35 $761-765$.

16. KOHN S G, Briele H A and Douglass L H. Volvulus complicating pregnancy. Am J Obster Gynecol 1944; 48 $398-404$.

17. Sharpton B and Cheek R C. Volvulus of the sigmoice colon, Am Surg 1976; June: 436-440.

18. SHEPHERD J J. Treatment of volvulus of sigmoid colon: review of 425 cases. Br Med J 1968; 1: 280-283.

19. Malkastan G D, Welch $J \mathrm{~S}$ and Hallenbeck G a Volvulus associated with pregnancy. Am J Obster Gyneco 1959; 78: 112-124. 